\title{
Reflexivity: Parent of a child with ASD
}

To the editor: As a parent of a child with autism spectrum disorder (ASD), I felt it necessary to write this reflexivity piece about my research journey around the topic of ASDs in the South African (SA) context. I have also chosen to include this section of my research that draws from the following statement by Guillemin and Gillam: ${ }^{[1]}$

'Our research interests and the research questions we pose, as well

as the questions we discard, reveal something about who we are.'

I was asked by the majority of my study participants why I had chosen to conduct a study of this nature. I initially found this question difficult and avoided answering it, but I soon realised that the question was unavoidable. As I could not divulge that I am a parent of a child with ASD I answered the question as follows: 'This topic is very important to me.'

One important aspect that interested me, was understanding how parents from disadvantaged backgrounds cope with the costs associated with raising a child with ASD. I have personally experienced the daunting process of consulting many different medical specialists without obtaining a diagnosis for my boy. I spent vast amounts on therapies and medications, and wanted to understand how a parent who was less privileged would cope with raising a child with ASD. Most of all, I needed to understand how the child's development might be affected by limited financial resources in the household.

Through conducting this study, I have gained immense knowledge and information on the topic of ASD within the SA context. The first discovery was that the SA government has created special grants for children and parents who are less privileged. Through these grants, parents who were less advantaged may be able to cater for the needs of their children.

The second discovery was that the SA government has opened schools that cater specifically for the educational needs of children diagnosed with ASD. However, there are too few schools available for all the children who have been diagnosed. Some schools have long waiting lists of parents who need a place for their children to be schooled.

As a final comment, embarking on a personal topic is an emotional process. There were moments in the field where I felt overwhelmed with emotions which were aroused by parents who were misinformed, lacked knowledge and sometimes were frustrated by the process of trying to gain services or even obtaining their child's diagnosis. Some of the struggles that these parents were experiencing were struggles that I personally relate to and experienced. Most of these parents were very keen to take part in the study with the hope that they might find answers or information to ease their frustration. Their anxiety was disheartening and left me with an even greater desire to pursue more research in the area of ASD in the SA context.

\section{Ayanda Purity Simelane}

Department of Psychology, Faculty of Humanities, The Wits Reproductive Health and HIV Institute, University of the Witwatersrand, Johannesburg, South Africa simelane.ayanda1@gmail.com

S Afr J Child Health 2017;11(3):108. DOI:10.7196/SAJCH.2017.v11i3.1422

1. Guillemin M, Gillam L. Ethics, reflexivity, and 'ethically important moments' in research. Qual Inq 2004;10(2):261-280. https://doi. org/10.1177/1077800403262360

2. Ryan L, Golden A. 'Tick the box please': A reflexive approach to doing quantitative social research. Sociology 2006;40(6):1191-1200. https://doi. org/10.1177/0038038506072287 